\title{
Photo-oxidation of organic compounds in the presence of titanium dioxide: determination of the efficiency
}

\author{
Frank Sabin, Thomas Türk and Arnd Vogler \\ Universität Regensburg, Institut für Anorganische Chemie, Universitätsstrasse 31, \\ W-8400 Regensburg (FRG)
}

(Received June 16, 1991; in revised form August 5, 1991; accepted August 6, 1991)

\begin{abstract}
The photo-oxidation of 23 compounds (benzene, haloaromatics, chloroalkenes, haloalkanes, bis-(2-chloroethyl)ether, 1-hydroxyethane-1, 1-diphosphonate and ethylenediamine$N, N, N^{\prime}, N^{\prime}$-acetic acid) in aqueous solution with titanium dioxide as the photocatyst was investigated. The plots of photo-oxidation rate $v s$. irradiation time were analysed on the basis of a simple kinetic model for homogeneous reactions. This model yielded formal rate constants which serve as a general measure for the efficiency of photo-oxidation.
\end{abstract}

\section{Intruduction}

The purification of polluted water such as waste water becomes a task of increasing importance in environmental protection. However, traditional technology has its limitations. A number of pollutants can be only degraded very slowly, incompletely or not at all by conventional procedures.

Accordingly new methods must be developed. The heterogeneous photocatalysis seems to be an attractive process for the degradation of many water pollutants. A wide variety of organic compounds such as chloroaromatics, chloroalkenes and haloalkanes are photo-oxidized to environmentally harmless $\mathrm{CO}_{2}$ and $\mathrm{HCl}$ (for a review sce ref. 1) [2-8]. Semiconductors such as $\mathrm{TiO}_{2}$ and $\mathrm{ZnO}$ were used as photocatalysts [1-5, 9-21] which remain unchanged during many reaction cycles [22]. Although much evidence has been accumulated that the photomineralization catalysed by semiconductors is of universal importance the efficiency of these photoreactions is generally unknown.

Usually the efficiency of a photoreaction is measured as a quantum yield. However, for heterogeneous photoreactions, quantum yield determinations are hampered by several complications such as light scattering. As an alternative, kinetic measurements can be used to evaluate the efficiency of a photoreaction. Complicated kinetic models may be of limited value since the molecular mechanism of a heterogeneous photoreaction is not well understood (for reviews see refs. 1 and 23) [24]. In our approach we applied a very simple kinetic model for homogeneous reactions and measured rate orders and constants. The influence of important parameters such as substrate concentration, light intensity, sample volume, input of oxygen, amount of dispersed $\mathrm{TiO}_{2}$ and $\mathrm{pH}$ were studied. Under standard conditions, formal rate constants were determined and may now be used as a scale of photo-oxidative efficiency. 


\section{Experimental details}

\subsection{Materials}

All chemicals were laboratory reagent grade and were used without further purification. The compounds were supplied by Merck (benzene, p.a.; chlorobenzene, p.a.; 1,2-dichlorobenzene, p.a.; bromobenzene, p.a.; 1,2-dichloroethylene, p.a., mixture of cis- and trans- isomers; trichloroethylene, p.a.; tetrachloroethylene, p.a.; tribromomethane, puriss.; 1,1,2,2-tetrachloroethane, p.a., 1,2-dichloropropane, 97\%; bis-(2chloroethyl)ether, 99\%; ethylenediamine- $N, N, N^{\prime}, N^{\prime}$-acetic acid (EDTA) Titriplex III, p.a.), Aldrich (pentachlorophenol (PCP), p.a.; $\gamma$-hexachlorocyclohexane, (Lindane) 97\%; dichloromethane, 99\%; trichloromethane, 99\%; tetrachloromethane, 99\%), Heraeus-PCR (1,1-difluoro-1,2,2-trichloroethane (FC 122); 1,1-difluoro-1,2-dichloroethane (FC 132b); fluorotrichloromethane (FC 11); 1,1,1-trifluoro-2,2,2-trichloroethane (FC 113)), Janssen Chimica (1,1-bis(4-chlorophenyl)-2,2,2-trichloroethane (DDT), 99\%) and Henkel (1-hydroxyethane-1,1-diphosphonate (HEDP)). Doubly distilled water was used as general solvent. The titanium dioxide $\left(\mathrm{TiO}_{2}\right)$ photocatalyst was Degussa P-25. This material is mainly anatase. According to the supplier the Brunauer-Emmett-Teller surface is $55 \pm 15 \mathrm{~m}^{2} \mathrm{~g}^{-1}$ and the average particle size $30 \mathrm{~nm}$.

\subsection{Photolysis}

Irradiation of all samples was carried out in a Photon Technology International set-up equipped with a $450 \mathrm{~W}$ xenon lamp (Osram). The light beam was focused on the photolysis cell (see below) by an elliptic mirror.

The samples contained $1.0 \mathrm{~g} \mathrm{TiO}_{2} \mathrm{I}^{-1}$. Samples were not buffered to avoid any interference by adsorption of buffer salts [25]. The $\mathrm{pH}$ of the samples was within the range 4.5-6.6 during irradiation. In order to keep $\mathrm{TiO}_{2}$ suspended and to achieve a sufficient supply of $\mathrm{O}_{2}$ to the solution, the sample was vigorously stirred at $1100 \mathrm{rev}$ $\min ^{-1}$ (procedure A) or $800 \mathrm{rev}^{\min ^{-1}}$ (procedure B) (Ika Combimag RCT magnetic stirrer) during the photolysis. All photolyses were carried out three times. For comparison, blank solutions were kept in the dark. The photo-oxidation rates could be reproduced by less than $5 \%$.

\subsection{Analysis procedure $A$}

All volatile compounds (benzene, chlorobenzene, 1,2-dichlorobenzene, bromobenzene, 1,2-dichloroethylene, trichloro ethylene, tetrachloroethylene, dichloromethane, trichloromethane, tetrachloromethane, tribromoethane, 1,1,2,2-tetrachloroethane, 1,2dichloropropane, bis-(2-chloroethyl)ether, 1,1-difluoro-1,2,2-trichloroethane (FC 122), 1,1-difluoro-1,2-dichloroethane (FC 132b), fluoro-trichloromethane (FC 11), and 1,1,1trifluoro-2,2,2-trichloroethane (FC 113)) were analysed by head-space gas chromatography. A Perkin-Elmer gas chromatograph 8500 equipped with an HS-6 head-space analyser, hot-wire detector, a packed column (length, $4 \mathrm{~m}$; diameter, $\frac{1}{8} \mathrm{in} ; 4 \%$ OV17 Chromosorb G AWDMCS; 80-100 mesh) and helium as carrier gas was used. As photolysis cell a Perkin-Elmer HS-6 round vessel (length, $3.7 \mathrm{~cm}$; diameter, $2 \mathrm{~cm}$ ) was used. It could be closed gas tight with a septum. The cell glass transmitted light above $320 \mathrm{~nm}$. The photolysis cell contained the sample solution $(2.0 \mathrm{ml})$ with the organic substrate $\left(c_{0}=1.0 \mathrm{mM}\right), 2.0 \mathrm{mg}$ of $\mathrm{TiO}_{2}$ and a small stirrer (length, $1.4 \mathrm{~cm}$; diameter, $0.3 \mathrm{~cm}$ ).

\subsection{Analysis procedure $B$}

Organic substrates which were not volatile (PCP, DDT, $\gamma$-hexachlorocyclohexane (Lindane), HEDP and EDTA) could not be analysed by head-space gas chromatography. 
In order to maintain a sufficient analytical sensitivity, a larger sample volume was employed for the photolysis. A Pyrex round tube (length, $20 \mathrm{~cm}$; diameter, $3 \mathrm{~cm}$ ) contained $30 \mathrm{ml}$ of a solution with a substrate concentration $c_{0}$ of $1.0 \mathrm{mM}, 30 \mathrm{mg}$ of $\mathrm{TiO}_{2}$ and a stirrer (length, $5 \mathrm{~cm}$; diameter, $0.7 \mathrm{~cm}$ ). Owing to the limited analytical sensitivity (see below) the concentration of HEDP was $5.0 \mathrm{mM}$. After irradiation the suspension was centrifuged. The disappearence of EDTA was determined by titration with $\mathrm{Ca}^{2+}$ [26]. Chloride as a photolysis product of PCP, DDT and Lindane was analysed by an Ingold ion-selective electrode. The irradiation of HEDP led to the formation of $\mathrm{H}_{3} \mathrm{PO}_{4}$ which was determined spectrophotometrically (Kontron Uvikon 860 spectrophotometer) as a heteropolyacid [27].

For a comparison of the results of procedures $A$ and $B$, chlorobenzene and 1,2dichlorobenzene were photolysed by both methods. Kinetic analysis yielded a conversion factor. Chlorobenzene and 1,2-dichlorobenzene were degraded $3.1 \pm 0.2$ times faster by procedure A than by procedure B. The data in Table 1 were normalized to procedure A by applying this conversion factor.

\section{TABLE 1}

First-order rate constants and half-lives for the catalytic photo-oxidation of organic substrates in the presence of $\mathrm{TiO}_{2}$ under standard conditions

\begin{tabular}{llr}
\hline Organic substrate & $\begin{array}{l}k \\
\left(\times 10^{-3} \mathrm{~s}^{-1}\right)\end{array}$ & $\begin{array}{c}\tau_{1 / 2} \\
\text { (min) }\end{array}$ \\
\hline Benzene & 2.4 & 4.8 \\
Chlorobenzene & 2.1 & 5.5 \\
1,2-dichlorobenzene & 3.5 & 3.3 \\
Bromobenzene & 0.3 & 37.5 \\
PCP $^{\mathrm{a}}$ & 5.5 & 2.1 \\
DDT $^{\mathrm{a}, \text { b }}$ & 2.8 & 4.3 \\
$1,2-$ dichloroethylene & 2.0 & 5.8 \\
Trichloroethylene & 2.3 & 5.1 \\
Tetrachloroethylene & 2.0 & 5.8 \\
Lindane & 1.2 & 9.4 \\
Dichloromethane & 1.9 & 6.0 \\
Trichloromethane & 0.6 & 18.0 \\
Tetrachloromethane & - & 5350 \\
Tribromomethane & 0.04 & 280 \\
1,1,2,2-tetrachloroethane & 1.5 & 8.0 \\
1,2-dichloropropane & 2.0 & 5.8 \\
Bis-(2-chloroethyl)ether & 3.2 & 4.0 \\
EDTA & 4.6 & 2.6 \\
FC 122 & 0.48 & 24.7 \\
FC 132b & 0.67 & 17.3 \\
FC 11 & - & - \\
FC 113 & - & - \\
\hline
\end{tabular}

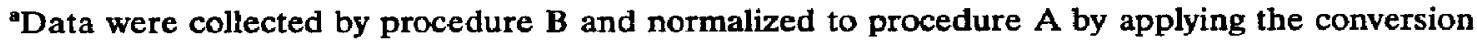
factor.

${ }^{b} \mathrm{O}$ wing to the low solubility in water $\mathrm{a}_{2} \mathrm{O}-\mathrm{CH}_{3} \mathrm{CN}$ mixture $\left(\mathrm{H}_{2} \mathrm{O}: \mathrm{CH}_{3} \mathrm{CN}, 1: 1\right)$ was employed as solvent.

No degradation was measured after an irradiation time of $300 \mathrm{~min}$. 


\section{Results and discussion}

The photo-oxidation of a wide variety of organic compounds in aqueous solutions catalysed by $\mathrm{TiO}_{2}$ has been reported. It is assumed that the electronically excited semiconductor reacts with adsorbed water, hydroxyl ions and oxygen. Thus the water or hydroxyl ions are oxidized to hydroxyl radicals $\mathrm{OH}^{*}$ by the valence band holes whereas the oxygen behaves as a trap for the conduction band electrons. In the first step of the reduction, superoxide ions $\mathrm{O}_{2}^{-}$are formed. The final product of the reduction may also be hydroxyl radicals $\mathrm{OH}^{*}$. The hydroxyl radicals can oxidize the compounds adsorbed onto the semiconductor surface $[10,13,24,28-30]$. In accordance with this mechanism the degradation of substrates takes place only in the presence of light, oxygen and $\mathrm{TiO}_{2}$. We confirmed these observations. In some cases it has been shown that the photo-oxidation led to complete mincralization of the organic substrate. For example, halocarbons are photo-oxidized according to the overall stochiometry $[1,5-7,31-33]$ :

$\mathrm{C}_{n} \mathrm{H}_{m} \mathrm{Cl}_{y}+x \mathrm{O}_{2} \underset{\mathrm{TiO}_{2}}{\stackrel{h \nu}{\longrightarrow}} n \mathrm{CO}_{2}+y \mathrm{HCl}+w \mathrm{H}_{2} \mathrm{O}$

However, an important aspect of these photo-oxidations has been largely neglected. For the purpose of comparison the relative efficiencies of the photolyses is mostly unknown. In the present work the relative efficiencies were determined by comparing the photo-oxidation rates of 23 organic compounds under equivalent conditions. The degradation rates as a function of irradiation time were recorded. Typical plots are shown in Figs. 1 and 2. All plots were then analysed in terms of formal kinetics.

The differential rate law for homogeneous reactions is

$\frac{-\mathrm{d} c}{\mathrm{~d} t}=k c^{n}$

where $c$ is the concentration of the organic substrate at irradiation time $c, k$ the reaction rate constant and $n$ the formal reaction order.

The transformation of the rate law yielded $n$. The analysis of the data revealed two limiting cases. As shown in Fig. 3, the photolyses of chlorobenzene proceeds according to zero-order kinetics (slope corresponding to $n-0$ ) at high substrate

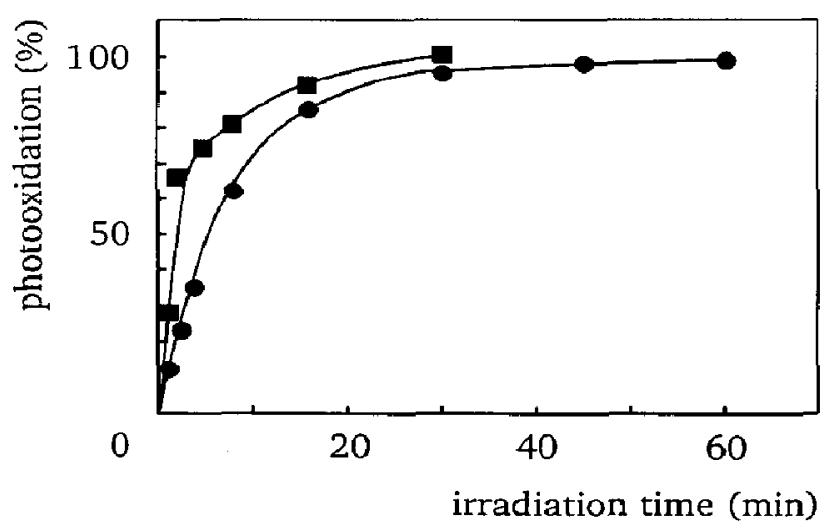

Fig. 1. Photo-oxidation rates of 1,2-dichloropropane (O) and bis-(2-chloroethyl)ether ( $\square$ ) as functions of irradiation time (procedure $\mathrm{A}$ ). 


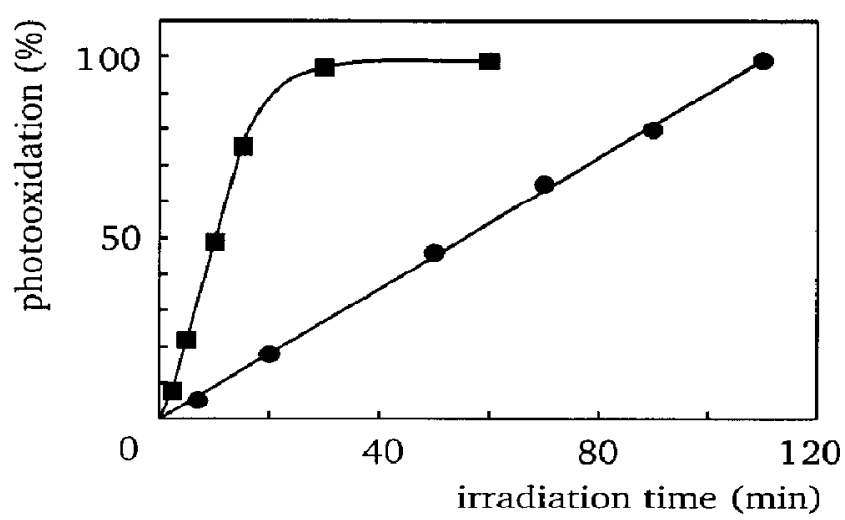

Fig. 2. Photo-oxidation rates of HEDP ( () and EDTA ( $\square$ ) as functions of irradiation time (procedure B; HEDP $c_{0}=5.0 \mathrm{mM}$ ).

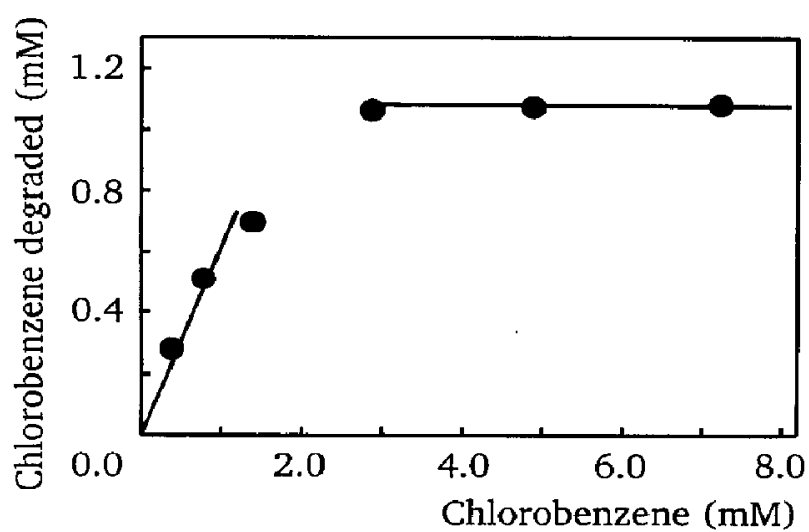

Fig. 3. Photo-oxidized chlorobenzene as a function of initial concentration of chlorobenzene in solution (procedure A; irradiation time, $5 \mathrm{~min}$ ).

concentrations (c>3 mM) while pseudo-first-order kinetics (slope corresponding to $n=1)$ are observed at low concentrations $(c<1.4 \mathrm{mM})$.

In terms of the Langmuir-Hinshelwood model $[2,5,6,31]$ this means that at high substrate concentrations all catalytic sites of the semiconductor surface are occupied. A further increase in substrate concentration does not effect the efficiency of the photo-oxidation. On the contrary, at low concentrations the number of catalytic sites is not the limiting factor of the degradation rate which is now proportional to the substrate concentration in accordance with apparent first-order kinetics. Similar results were obtained for trichloromethane.

With the exception of HEDP the concentrations of all other substrates could be kept low enough to ensure first-order kinetics. In the case of HEDP (Fig. 2) the analytical limit of product detection required a higher concentration which yielded zeroth-order kinetics $(n=0)$.

At low substrate concentrations the integral rate law for $n=1$ is

$c=c_{0} \mathrm{e}^{-k t}$

where $c_{0}$ is the concentration of the solution at irradiation time $t=0$. By transforming eqn. (2) the first-order rate constant $k$ and half-life $\tau_{1 / 2}$ could be derived. 


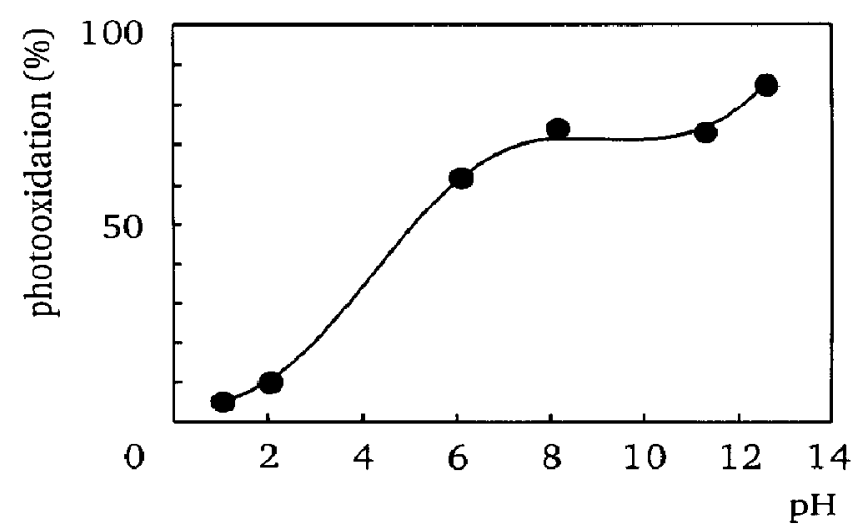

Fig. 4. Photo-oxidation rate of chlorobenzene as a function of $\mathrm{pH}$ (procedure $\mathrm{A}$; irradiation time, $10 \mathrm{~min}$; buffered solutions).

The first-order rate constants and half-lives are summarized in Table 1. These rate constants may be used as relative efficiencies of photo-oxidation. Although the limited data set does not allow any generalization, some trends are apparent. The photolysis of chlorinated alkanes seems to be less efficient than that of chlorinated alkenes and aromatic compounds. Similar results were reported by other workers [2, $7,34,35]$.

In accordance with our results, Ollis et al. [7] and Tanaka and workers [34] reported also a decreased degradation rate if $\mathrm{C}-\mathrm{H}$ bonds are replaced by $\mathrm{C}-\mathrm{Cl}$ bonds in methane. If the substitution is complete, the decline in photo-oxidation efficiency is most striking. The photo-oxidation of haloalkenes and haloaromatics seems to be influenced less by the number of $\mathrm{C}-\mathrm{Cl}$ bonds. This is demonstrated by the observation that there is little variation in the half-lives of benzene, chlorobenzene and 1,2dichlorobenzene, 1,2-dichloroethylene, trichloroethylene and tetrachloroethylene (Table 1).

A further decrease of photo-oxidation efficiency was observed for fluorinated alkanes (Table 1). In contrast with previous results the compounds FC 11 and FC 113 were not photo-oxidized at all [33].

In contrast with previous studies [33] we observed a large decrease in the photooxidation efficiency when chlorinated halocarbons (chlorobenzene and trichloromethane) are compared with the respective brominated halocarbons (bromobenzene and tribromomethane). This observation is surprising because the $\mathrm{C}-\mathrm{Br}_{\mathrm{r}}$ bonds are weaker than $\mathrm{C}-\mathrm{Cl}$ bonds (280 vs. $397 \mathrm{~kJ} \mathrm{~mol}^{-1}$ ) [36]. As a possible explanation the adsorption of brominated compounds onto the surface of $\mathrm{TiO}_{2}$ may be slower or weaker than that of the chlorinated compound.

Finally it was of interest to study the influence of $\mathrm{pH}$ on the photo-oxidation since the photolysis is accompanied by the release of protons (see above). The photooxidation efficiency may then change because of a reversible protonation of the $\mathrm{TiO}_{2}$ surface $[8,17,31,32]$. As an example the degradation rate of chlorobenzene in buffered [37] solutions was studied (Fig. 4). At a $\mathrm{pH}$ range from 6 to 11 the degradation rate remains constant. At $\mathrm{pH}<6$ the degradation rate decreases strikingly whereas at $\mathrm{pH}>11$ the reaction is accelerated. Similar effects were also observed by other groups $[4,12]$. 


\section{Conclusions}

The photo-oxidation of 23 organic compounds including four fluorochloroalkanes in aqueous $\mathrm{TiO}_{2}$ suspensions was studied. On the basis of a simple kinetic model the relative efficiency of photo-oxidation of the various compounds could be determined. The totally halogenated FC 113 and FC 11 could not be degraded at all. Benzene, chloroaromatics, chloroalkenes, chloroalkanes and EDTA had half-lives from 3 to 9 min. Bromobenzene, tribromomethane, trichloromethane, tetrachloromethane, FC 122 and FC 132b were photo-oxidized strikingly slower with half-lives from 18 to $350 \mathrm{~min}$. At low concentrations of the organic compound $\left(c_{0}<1.4 \mathrm{mM}\right)$ pseudo-first-order kinetics were observed. At high concentrations $\left(c_{0}>3 \mathrm{mM}\right)$, photo-oxidation obeyed zero-order kinetics.

\section{Acknowledgments}

We thank S. Ponwitz for help in collecting data and Dr. H. Kunkely for encouragement and discussion. We thank the Degussa $\mathrm{AG}$, Frankfurt for providing $\mathrm{TiO}_{2}$ P-25 and Henkel KGaA, Düsseldorf, for supplying HEDP. Financial support by the Bundesministerium für Forschung und Technologie is gratefully acknowledged.

\section{References}

1 D. F. Ollis, E. Pelizetti and N. Serpone, in N. Serpone and E. Pelizetti (eds.), Photocatalysis, Wiley, New York, 1989, pp. 603-637, and references cited therein.

2 R. W. Matthews, J. Catal., 111 (1988) 264-272.

3 C. S. Turchi and D. F. Ollis, J. Catal., 119 (1989) 483-496.

4 J.-C. D'Oliveira, G. Al-Sayyed and P. Pichat, Environ. Sci. Technol., 24 (1990) 990-996.

5 R. W. Matthews, Water Res., 24 (1990) 653-660.

6 A. L. Pruden and D. F. Ollis, J. Catal., 82 (1983) 404-417.

7 D. F. Ollis, C.-H. Hsiao, L. Budiman and C.-H. Lee, J. Catal., 88 (1984) 89-96.

8 M. Barbeni, E. Pramauro, E. Pelizetti, E. Borgarello and N. Serpone, Chemosphere, 14 (1985) 195-208.

9 K. Harada, T. Hisanaga and K. Tanaka, New J. Chem., 11 (1987) 597-600.

10 E. Pelizetti, M. Borgarello, C. Minero, E. Pramauro, E. Borgarello and N. Serpone, Chemosphere, 17 (1988) 499-510.

11 H. Hidaka, S. Yamada, S. Suenaga, H. Kubota, N. Serpone, E. Pelizetti and M. Grätzel, J. Photochem Photobiol. A: Chem., 47 (1989) 103-112.

12 K. Tanaka, T. Hisanaga and K. Harada, J. Photochem. Photobiol A: Chem., 48 (1989) $155-159$.

13 E. Pelizetti, C. Minero, V. Maurino, A. Sclafani, H. Hidaka and N. Serpone, Environ. Sci. Technol., 23 (1989) 1380-1385.

14 S. Yamagata, R. Baba and A. Fujishima, Bull. Chem. Soc. Jpn., 62 (1989) 1004-1010.

15 C. Minero, V. Maurino, L. Campanella, C. Morgia and E. Pelizetti, Environ. Technol. Lett., 10 (1989) 301-310.

16 T. Sehili, P. Boule and J. Lemaire, J. Photochem. Photobiol. A: Chem., 50 (1989) 103-116.

17 T. Sehili, P. Boule and J. Lemaire, J. Photochem. Photobiol. A: Chem., 50 (1989) 117-127.

18 K. Harada, T. Hisanaga and K. Tanaka, Water. Res., 24 (1990) 1415-1417.

19 H. Hidaka, S. Yamada, S. Suenaga, J. Zhao, N. Serpone and E. Pelizetti, J. Mol. Catal., 59 (1990) 279-290. 
20 C. K. Grätzel, M. Jirousek and M. Grätzel, J. Mol. Catal., 60 (1990) 375-387.

21 E. Pelizetti, V. Maurino, C. Minero, V. Carlin, E. Pramauro and O. Zerbinati, Environ. Sci. Technol., 24 (1990) 1559-1565.

22 M. Barbeni, M. Morello, E. Pramauro, E. Pelizetti, M. Vincenti, E. Borgarello and N. Serpone, Chemosphere, 16 (1987) 1165-1179.

23 F. Pichat and J.-M. Ierrmann, in N. Serpone and E. Pelizetti (eds.), Photocatalysis, Wiley, New York, 1989 , pp. 217-250, and references cited therein.

24 C. S. Turchi and D. F. Ollis, J. Catal, 122 (1990) 178-192.

25 M. Abdullah, C. K.-C. Low and R. W. Matthews, J. Phys. Chem., 94 (1990) $6820-6825$.

26 N. Wiberg, Lehrbuch der Anorganischen Chemie, Walter de Gruyter, Berlin, 1985, p. 920.

27 B. Lange and Z. J. Vejdelek, Photometrische Analyse, Verlag Chemie, Weinheim, 1980, pp. 374-375.

28 V. Augugliaro, L. Palmisano, A. Sclafani, C. Minero and E. Pelizetti, Toxicol. Environ. Chem., 16 (1988) 89-109.

29 J. Cunningham and S. Srijarani, J. Photochem. Photobiol. A: Chem., 43 (1988) 329-335.

30 H. Al-Ekabi, N. Serpone, E. Pelizetti, C. Minero, M. A. Fox and R. B. Draper, Langmuir, 5 (1989) 250-255.

31 C.-Y. Hsiao, C.-L. Lee and D. F. Ollis, J. Catal, 82 (1983) 418-423.

32 A. L. Pruden and D. F. Ollis, Environ. Sci Technol., 17 (1983) 628-631.

33 D. F. Ollis, Environ. Sci. Technol., 19 (1985) $480-484$.

34 T. Hisanaga, K. Harada and K. Tanaka, J. Photochem. Photobiol. A: Chem., 54 (1990) 113-118.

35 H. Hidaka, H. Kubota, M. Grätzel, N. Serpone and E. Pelizetti, Nouv. J. Chim., 9 (1985) $67-69$.

36 Handbook of Chemistry and Physics, 63rd edn., CRC Press, West Palm Beach, FL, 1982-1983, p. F 186.

37 Handbook of Chemistry and Physics, 63rd edn., CRC Press, West Palm Beach, FL, 1982-1983, p. D 155. 